\title{
Policy Assistance for Adoption of Residential Solar PV in India: A Stakeholder-centric Approach for Welfare Optimization
}

Vivek Mohan ( $\nabla$ vivekmohangokulam@gmail.com )

National Institute of Technology Tiruchirappalli https://orcid.org/0000-0002-3304-7150

Harish Ram D S

Amrita Vishwa Vidyapeetham

Ganesh Patil

NIT-Tiruchirappalli: National Institute of Technology Tiruchirappalli

Jisma M

NIT-Tiruchirappalli: National Institute of Technology Tiruchirappalli

\section{Rohith C Unni}

Auroville Consulting

Nandakumar K

Kerala State Electricity Board Limited

Karthik Thirumala

NIT-Tiruchirappalli: National Institute of Technology Tiruchirappalli

Siqi Bu

The Hong Kong Polytechnic University

Original article

Keywords: Feed-in-Tariff, Rooftop Solar PV, Policy, India, Energy

Posted Date: August 5th, 2021

DOI: https://doi.org/10.21203/rs.3.rs-752988/v1

License: (c) (1) This work is licensed under a Creative Commons Attribution 4.0 International License.

Read Full License 


\title{
1 Policy Assistance for Adoption of Residential Solar PV in India: A
}

\section{Stakeholder-centric Approach for Welfare Optimization}

\author{
3 Vivek Mohan ${ }^{1 *}$, Harish Ram D S ${ }^{2}$, Ganesh Patil ${ }^{1}$, Jisma $\mathrm{M}^{1}$, Rohith C Unni ${ }^{3}$, Nandakumar $\mathrm{K}^{4}$, \\ Karthik Thirumala ${ }^{1}$, Siqi $\mathrm{Bu}^{5}$ \\ ${ }^{1}$ Department of Electrical and Electronics Engineering, National Institute of Technology \\ Tiruchirappalli, TN, India \\ ${ }^{2}$ SIERS Research Laboratory, Department of Electronics and Communication Engineering, \\ Amrita School of Engineering, Coimbatore, Amrita Vishwa Vidyapeetham, India \\ ${ }^{3}$ Auroville Consulting, Kalpana Community, Auroville, TN, India \\ ${ }^{4}$ Transgrid Construction Subdivision, Kerala State Electricity Board Limited, Kerala, India \\ ${ }^{5}$ Department of Electrical Engineering, The Hong Kong Polytechnic University, Hong Kong \\ *Email: vivekmohangokulam@gmail.com, harishramds@gmail.com
}

\begin{abstract}
Background: Domestic solar PV installations in India are yet to become a valuable proposition for both the prosumers and utility because of the deficiencies in the formulation of the policy parameters. This paper presents a comprehensive analysis of the consumer-centric business model for rooftop solar PV installations in India. We explore areas where potential policy interventions may be introduced to improve collective stakeholder benefits and incentivize more domestic consumers to install rooftop solar panels in their premises. We propose a policy framework that seeks optimal Feed-in Tariff (FiT) rates, PV capacities and Average Billing Rates (ABRs) towards maximizing stakeholder benefits. The stakeholders considered are the consumers/prosumers and the utility.
\end{abstract}

Results: Case studies with three residential prosumers of different demand and generation profiles (extracted from data provided by Indian utilities) are presented. A multi-objective problem is formulated with the FiT, generation capacity (as a function of demand) and $\mathrm{ABR}$ as decision variables, exploring the various welfare trade-offs. The pareto-optimal front is identified for prosumer and utility benefits and suitable points with reasonable tradeoff are selected based on sensitivity analysis of the impact of the decision variables on collective welfare.

Conclusions: The paper provides a workflow to fix tariff, FiT and local PV capacities in active residential distribution systems. The suitability of prevailing tariff and FiT rates of three Indian utilities namely, MSEDCL, TATA POWER (Delhi) and TANGEDCO are studied, and their impact on prosumer savings and utility profits is brought out. The paper recommends optimal 
installation capacities for prosumers based on their load demand so as to encourage the adoption of roof-top solar without affecting collective benefits. This provides policymakers and prosumers an effective decision-making tool. Keywords — Feed-in-Tariff, Rooftop Solar PV, Policy, India, Energy

\section{Background}

Roof-Top solar PV installations are one of the major approaches proposed to promote distributed generation in India [1]. The market potential for roof-top solar generation is $352 \mathrm{GW}$ out of which $124 \mathrm{GW}$ is technically feasible. The Ministry of New and Renewable Energy, Government of India has set a target of 40,000MW of roof-top solar generation by 2022. This accounts for $40 \%$ of the total solar power generation capacity envisaged by 2022 [2]-[3].

37 Successful adoption of rooftop PV is vital from the perspective of reducing carbon emissions for which a commitment of 33-35\% reduction by 2030 has been given by India in the Paris Climate Conference in [4]-[5]. It also calls for concerted efforts to educate the consumers on the long term economic [6] and environmental benefits. The successful implementation of this target depends on multiple socio-economic and technical factors such as prevalence of appropriate business models [7] that consider the interests of all stakeholders viz., prosumers, utilities [8], third-party agencies, state, and central governments. governments have been reported worldwide. In [9], recommendations for devising policies and tariff structures for adoption of roof-top solar in low irradiance regions are put forward. The relationship between different income levels and solar uptake in Australia is analyzed in [10], thereby bringing out a case for detailed study of socio-economic indicators for policy updates. In [11]-[12], reduction in $\mathrm{CO}_{2}$ emissions by upgrading all households to comply with energy star standards combined with increased roof-top solar PV installations and optimization for net zero energy homes are addressed. A case-study of a PV agricultural business model is presented in [13] in which greenhouses with rooftop PVs generate revenue from PV generation whereas the greenhouse space is leased out to agricultural ventures

51 thus creating a complete entrepreneurial ecosystem. The lack of penetration of distributed PV among socio-poor 52 sections in California is analyzed using a comprehensive metric CalEnviroScreen (CES) in [14]. In [15], the effect of 53 an information campaign in promoting rooftop solar PV installations is quantitatively assessed. The authors report a 54 significant increase in the number of approved applications post the campaign. Agent Based Models are used for 
simulating solar PV adoption in Great Britain by integrating different socio-economic factors in [16]. The authors provide insights into how different subsidy regimes impact the adoption of the scheme. is presented in [17]-[18]. The paper compiles inputs from various stakeholders across different socio-economic and professional categories in the governmental and private sectors. In [19]-[20], comparison of bill saving under net metering [21] to that received under three potential compensation mechanisms is presented. The analysis shows the extent to which net metering can produce significant bill savings across customers. In [22]-[23], new FiT structures that consider electricity price dependence, capacity pricing and energy pricing are proposed to address both individual and societal benefits. The sensitivity of collective benefits to uncertainties in rooftop solar energy output are analyzed using stochastic models in [24]. However, these studies present conclusions based on surveys and feedback questionnaires without analytically modelling the stakeholder benefits. In [25]-[26], the economic viability of the solar PV system is evaluated at different capacities based on net present value (NPV), internal rate of return (IRR) and PayBack-Period. The authors show that profitability is highest when net-metering or self-consumption is active but do not provide any recommendations for the optimal settings of PV capacity and FiT. In [27]-[29], the FiT framework, business models and bidding criteria for the support of solar power production in Thailand, USA and India along with the key barriers for adoption are identified with possible remedies such as tax incentives and attractive financing options. In [30], Australia's solar energy policies in terms of FiTs are studied. The study brings out the importance of

72 FiTs in household PV adoption.

74 adoption of distributed roof-top solar PV are being conceived. They include bringing in energy star ratings, new 75 business models, incentivizing low carbon sources, improving ease of establishing renewable powered businesses and 76 agricultural activity, tariff restructuring, subsidies, aggressive campaigning etc. In India, the power distribution sector

77 is still under the process of deregulation with the utility playing a dominant role in financial and technical decision 78 making. The end consumer has no choice in buying and selling (locally generated) power since only a single utility 79 caters to a particular area. Therefore, the present policy scenario does not permit drastic transformation through complete market liberalization. Nevertheless, tuning of prevailing policy parameters like FiT, ABR and PV capacity can definitely make local roof-top solar PV installations an attractive proposition for both prosumers and utilities. In 
this paper, the effect of rooftop solar on prosumer savings and utility profit is analyzed for a consumer-centric business model in India. Given the conflicting nature of the objectives namely, prosumer savings and utility profit, a multiobjective problem is formulated with FiT, ABR, Prosumer Demand and PV capacity as decision variables to generate the pareto front. The study explores the net feed-in mechanism by providing room for flexibility in searching the range of FiT values. The sensitivity of the objectives to FiT and PV capacity under the prevailing values of ABR and ACOS is analyzed to extract pareto points providing reasonable trade-offs for the stakeholders. Three Indian utilities, MSEDCL, TATA POWER, Delhi and TANGEDCO are considered for the study based on availability of data. Policy recommendations are provided for tuning the FiT, ABR and PV capacity for the aforementioned utilities.

The paper is organized as follows: Section 2 describes the methodology adopted for modeling the stakeholder benefits and their pareto optimization. Section 3 presents the results of sensitivity analysis and multi-objective optimization along with the policy recommendations. Section 4 lists out policy suggestions with concluding remarks and outlines future directions.

\section{Methodology}

The prevailing business models for roof-top solar implementation in India are: 1) Consumer centric, 2) Renewable Energy Service Company (RESCO) based, and 3) Utility facilitated. In the consumer centric model, the consumer bears the capital and operational expenditure for the rooftop installation and has complete ownership of the system. In the RESCO based model, the RESCO sets-up the PV system on the rooftop of the customer and signs a PPA (Power Purchase Agreement) with the consumer. The investment is recovered through the solar energy tariff. In the utility facilitated model, the installation is owned and managed by the utility with the prosumer compensated either through bill discounts or other incentives.

In this paper, two types of residential premises are considered. The ones with installed rooftop solar PV panels are called prosumers. Those without local self-generation are referred to as consumers. The case study is confined to residential prosumers/consumers in the low voltage distribution system. The prosumers are classified into three categories based on the range of installed PV capacities. In India, maximum permissible PV capacities are limited to 8-10 kW depending on the utility. The categories are 1-3 kW, 3-5 kW and 5-8 kW. The classification is necessitated because a single policy recommendation for the entire range of $1-8 \mathrm{~kW}$ is impractical due to the large difference in 
capital investment cost. The stakeholders are the prosumers and the utility. The benefit of the prosumer is modelled in terms of the savings obtained on adoption of rooftop solar after considering the EMI outgo towards the installation cost and income from sale of locally generated rooftop solar energy. The benefit of the utility is the profit earned from

111 the sale of energy at ABR after considering the cost of procurement of energy. The formulation of the prosumer savings and utility profit equations is explained in detail in Section 2.1. The trade-offs involved in ensuring reasonable benefits for the stakeholders are explored by tuning the key decision variables related to installed capacity, load demand and feed-in-tariff rates.

\section{Modelling the economics of stakeholders}

The consumer-centric business model shown in Fig.1 is analysed in this paper. In this model, the potential prosumer has to bear the complete capital and operational expenditure of the rooftop solar PV installation. The consumer contacts an EPC firm to set up the installation at his/her premises. Based on the metering regulation, the financial and energy settlements are done through net or gross-metering arrangements [31]. The prosumer consumes the locally generated solar energy, and the surplus energy is exported to the utility at Feed-in-Tariff. In case, the local generation is not sufficient, the prosumer imports energy from the utility at retail tariff rate.

122

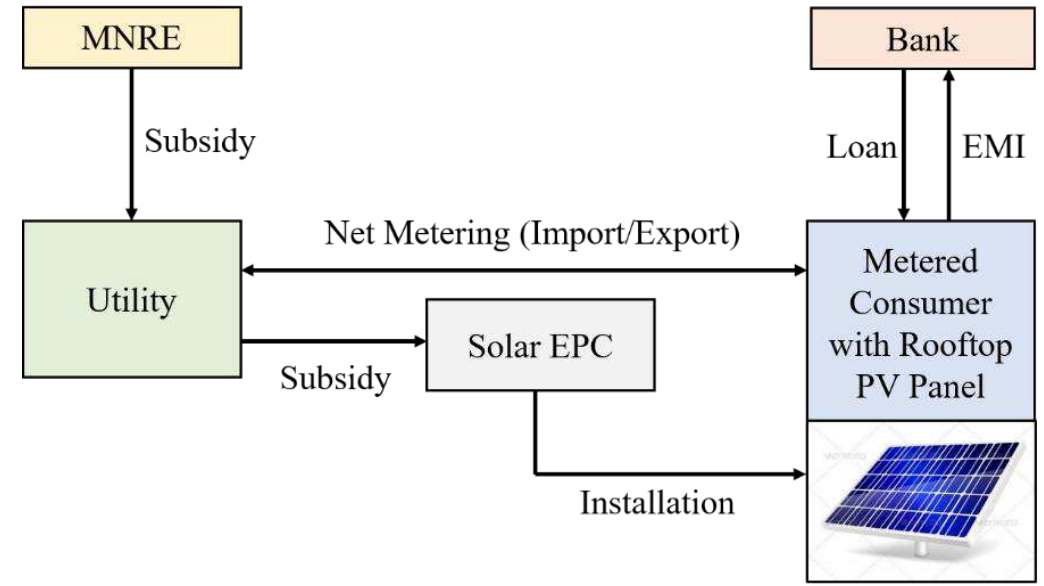

Fig. 1. Consumer-centric business model

The equations describing the components of the utility profit and prosumer savings are given in Table 1. Revenue and expense of the utility are modelled by equations (1) and (2) respectively. The terms of equations (1) are described in rows 1-3 of Table 1. The terms of equation (2) are specified in Rows 5 and 6 respectively. The term $\mathrm{k}$ is defined as shown in equation (3). Its value depends on whether the prosumer has an excess or deficit of energy. The profit of utility is shown in equation (4). The monthly electricity bill that the prosumer would have incurred in 

and 11 of Table 1. Equation (6) computes the prosumer's electricity bill considering local generation from solar PV. Its terms are explained in rows 13,14, 15 and 17 of Table 1. EMI is calculated using equation (7) where p is the total installation cost, $\mathrm{r}$ is the rate of interest and $\mathrm{n}$ is the payback period. The savings of prosumers is modelled by equation (8).

\begin{tabular}{|c|c|c|c|}
\hline $\begin{array}{l}\text { Row } \\
\text { No. }\end{array}$ & Term & \multicolumn{2}{|l|}{ Description } \\
\hline 1 & $\left(E_{d c} \times a b r\right)$ & \multicolumn{2}{|c|}{$\begin{array}{l}\text { Earnings from the sale of energy at ABR to non-rooftop } \\
\text { solar consumers }\end{array}$} \\
\hline 2 & $\left(E_{g p}-E_{d p}\right) \times(k-1) \times a b r$ & \multicolumn{2}{|c|}{$\begin{array}{l}\text { Earnings from the sale of deficit energy at ABR from } \\
\text { prosumer }\end{array}$} \\
\hline 3 & $F C \times\left(n_{p}+n_{c}\right)$ & \multicolumn{2}{|c|}{ Fixed monthly charge from the prosumers and consumers } \\
\hline 4 & \multicolumn{2}{|c|}{$R e v_{u t i}=\left(E_{d c} \times a b r\right)+\left\{\left(E_{g p}-E_{d p}\right) \times(k-1) \times a b r\right\}+F C \times\left(n_{p}+n_{c}\right)$} & $(1)$ \\
\hline 5 & $k \times\left(E_{g p}-E_{d p}\right) \times F i T$ & \multicolumn{2}{|l|}{ Purchase of energy from prosumers at FiT } \\
\hline 6 & $\left\{E_{d c}-\left(E_{g p}-E_{d p}\right)\right\} \times a c o s$ & \multicolumn{2}{|c|}{$\begin{array}{l}\text { Purchase of remaining energy to meet the demand of the } \\
\text { system from the upstream grid at ACoS }\end{array}$} \\
\hline 7 & \multicolumn{2}{|c|}{$\operatorname{Exp}_{u t i}=k \times\left(E_{g p}-E_{d p}\right) \times F i T+\left\{E_{d c}-\left(E_{g p}-E_{d p}\right)\right\} \times a c o s$} & $(2)$ \\
\hline 8 & \multicolumn{2}{|c|}{$k= \begin{cases}1 & \left(E_{g p}-E_{d p}\right)>0 \\
0 & \left(E_{g p}-E_{d p}\right)<0\end{cases}$} & (3) \\
\hline 9 & \multicolumn{2}{|c|}{$\begin{aligned} \text { Profit }_{u t i}= & {\left[\left\{E_{d c} \times(a b r-a c o s)\right\}-\left\{\left(E_{g p}-E_{d p}\right) \times(a b r \times(1-k)-a c o s)\right\}\right]+} \\
& {\left[F C \times\left(n_{p}+n_{c}\right)\right]-\left[k \times\left(E_{g p}-E_{d p}\right) \times F i T\right] }\end{aligned}$} & $(4)$ \\
\hline 10 & $E_{d p} \times a b r$ & \multicolumn{2}{|l|}{ Cost of purchase of energy at ABR by prosumer } \\
\hline 11 & $F C \times n_{p}$ & \multicolumn{2}{|l|}{ Monthly fixed charge by prosumer } \\
\hline 12 & \multicolumn{2}{|c|}{ Bill $_{\text {without solar }}=E_{d p} \times a b r+F C \times n_{p}$} & $(5)$ \\
\hline 13 & $(1-k) \times\left(E_{d p}-E_{g p}\right) \times \mathrm{abr}$ & \multicolumn{2}{|l|}{ The cost of purchase of deficit energy at ABR } \\
\hline 14 & $\left(E_{d p}-E_{g p}\right) \times F i T \times k$ & \multicolumn{2}{|l|}{ The revenue from the sale of surplus energy at FiT } \\
\hline 15 & $F C \times n_{p}$ & \multicolumn{2}{|l|}{ Monthly fixed charge by prosumer } \\
\hline 16 & \multicolumn{2}{|c|}{ Bill $_{\text {with solar }}=(1-k) \times\left(E_{d p}-E_{g p}\right) \times \mathrm{abr}+\left(E_{d p}-E_{g p}\right) \times F i T \times k+F C \times n_{p}+E M I$} & $(6)$ \\
\hline 17 & \multicolumn{2}{|l|}{$\mathrm{EMI}=\mathrm{p} \times \mathrm{r} \times \frac{(1+r)^{n}}{(1+r)^{n}-1}$} & $(7)$ \\
\hline
\end{tabular}




$$
\begin{aligned}
& 18 \quad \text { Saving } \text { pro }=\text { Bill }_{\text {without solar }}-\text { Bill }_{\text {with solar }} \\
& =\left[E_{d p} \times a b r+F C \times n_{p}\right]-\left\{\left(E_{d p}-E_{g p}\right) \times[(1-k) \times a b r+F i T \times k]+\right. \\
& \left.F C \times n_{p}+E M I\right\}
\end{aligned}
$$

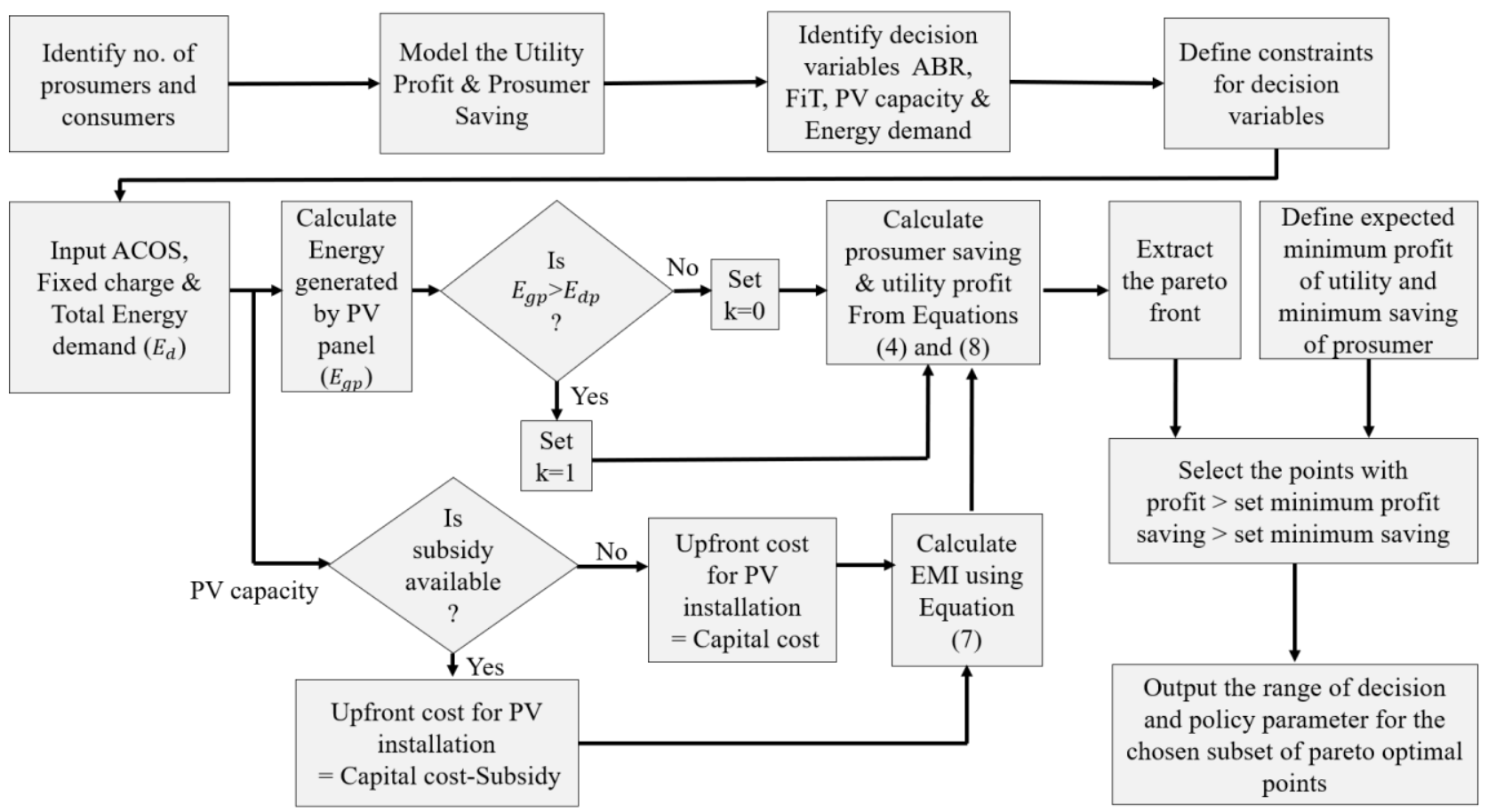

From equations (4) and (8), it is evident that the utility profit and prosumer savings depend on the following parameters: a) Feed-in Tariff (FiT) b) ABR c) PV panel size and d) Monthly Energy Demand of prosumer ( $\left.E_{d p}\right)$. Among these parameters, FiT and ABR are fixed by the utility whereas PV capacity and $E_{d p}$ are decided by the prosumers. The ABR values are derived from the category-wise revenue numbers of the utility [32]. ACoS is defined as the ratio of the total cost for providing power supply to the end consumer to total electricity input/purchased for the total number of consumers [33].

\section{Determination of pareto-optimal solution}

The objective functions are utility profit and prosumer savings given respectively in equations (4) and (8).

They are found to be conflicting in nature thereby necessitating a multi-objective optimization approach to explore and identify reasonable trade-offs from the pareto front shown in Figure. 3. 
The methodology to assist policy makers in identifying suitable ranges for the parameters ABR, FiT, PV capacity and Energy Demand is depicted in Figure 2. At the outset, the number of consumers and prosumers is defined. This is followed by development of profit and savings equations for the selected business model (consumer-centric in this case). Then the constraints to the multi-objective algorithm are defined in terms of the maximum and minimum limits of the decision variables. The value of $\mathrm{k}$ is set to 1 if the energy generated by solar is greater than the energy demand of the prosumer and is set to 0 otherwise. The prevailing ACoS and fixed charge of utility along with the EMI and set $\mathrm{k}$ values are used for profit and saving calculations using equations (4) and (8). Finally, the pareto front as shown in Fig.3 is extracted using non-dominated sorting algorithm. The minimum expected utility profit and prosumer savings are first laid down by the policy makers to ensure that rooftop PV installations are an attractive proposition for the prosumers. Also, the scheme must be designed in such a way that it is viable to the utility. Keeping these in mind, a subset of points in the pareto front is chosen, thus yielding the rationalized range of ABR, FiT, rooftop PV capacity and load demand. This serves as a guideline for framing policy recommendations.

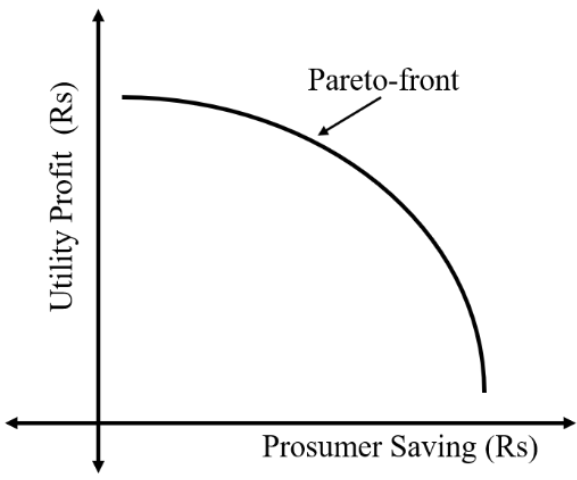

\section{Results and Discussion}

The proposed methodology is applied to evaluate a distribution test system having two prosumers and three consumers. The search space of the multi-objective optimization algorithm is defined by the constraints of the decision variables FiT, PV size, and $E_{d p}$ as shown in Table. 2 [34]-[36].

Three Indian utilities namely MSEDCL, TANGEDCO, and TATA power are considered for the study with their 
TABLE. 2. RANGES OF DECISION VARIABLES AND CONSTRAINTS

\begin{tabular}{|l|l|l|l|}
\hline Parameter & MSEDCL & TATA & TANGEDCO \\
\hline ABR $(\mathrm{Rs} / \mathrm{kWh})$ & 7.32 & 4.96 & 4.32 \\
\hline $\mathrm{ACoS}(\mathrm{Rs} / \mathrm{kWh})$ & 7.61 & 7.31 & 5.85 \\
\hline FiT $(\mathrm{Rs} / \mathrm{kWh})$ & \multicolumn{2}{|c|}{$1-4.2$} \\
\hline$E_{d p}(\mathrm{kWh})$ & \multicolumn{2}{|c|}{$50 \%$ to $150 \%$ of $E_{g p}\left(50 \%\right.$ of $E_{g p}$ for sensitivity analysis $)$} \\
\hline PV capacity $(\mathrm{kW})$ & \multicolumn{2}{|c|}{$1-8$} \\
\hline
\end{tabular}

171 Case 1: MSEDCL (Maharashtra)

172 The pareto-optimal points for different PV panel sizes are shown in Fig.4 in which absolute values of 173 prosumer saving are plotted against the utility profit. Fig.4 suggests that the best trade-offs for absolute values of 174 utility profit and prosumer savings are in the range of 5-8 kW PV capacities. However, 1-3 kW PV capacities yield 175 reasonable trade-offs in terms of percentages (see Table 6).

176

177

178

179

180

181

182

183

184

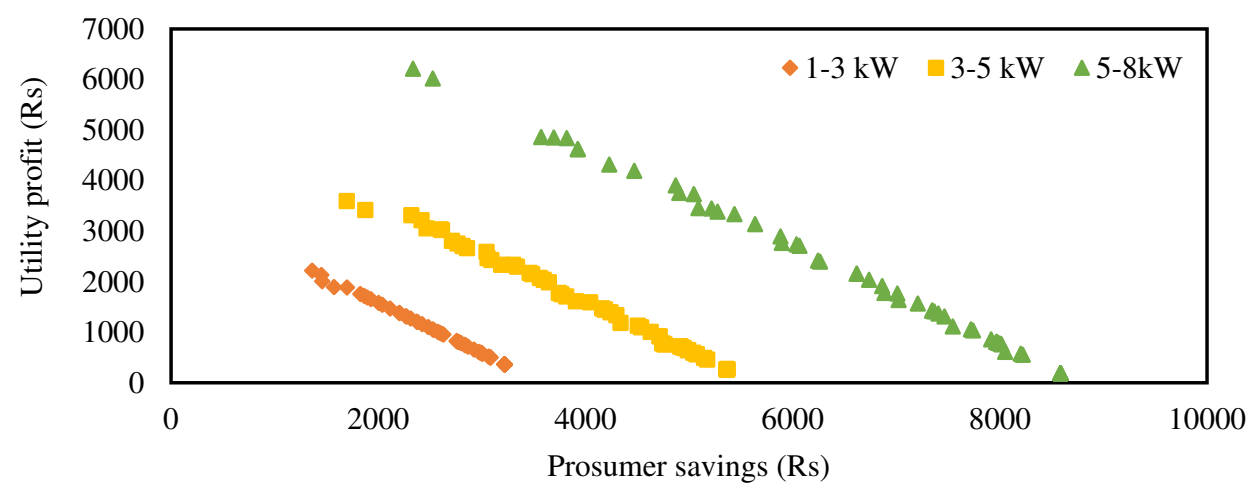

Fig. 4. Pareto optimal points for different PV ranges

Table. 3 and Table. 4 present the sensitivity analysis of utility profit and prosumer savings with respect to variations in FiT and PV capacities respectively for 1-3 kW and 3-5 kW. The sensitivity analysis is carried out for $E_{d p}$ values ranging from $50 \%$ to $150 \%$ of $E_{g p}$ in steps of $25 \%$. A representative case where $E_{d p}$ is $50 \%$ of $E_{g p}$ is depicted in Tables 3, 4 and 5. From Table 3, it is evident that prosumer savings increase with installed capacity only for FiTs above $2.2 \mathrm{Rs} / \mathrm{kWh}$ when local prosumer generation exceeds prosumer demand $\left(E_{g p}>=E_{d p}\right)$. For FiT $>=2.2 \mathrm{Rs} / \mathrm{kWh}$, the utility profit and prosumer savings range from $11 \%$ to $28 \%$ and $51 \%$ to $66 \%$ respectively. This is observed at $E_{d p}$ values ranging from $55 \%$ to $95 \%$ of $E_{g p}$. For the lowest range of 1 to $3 \mathrm{~kW} \mathrm{PV} \mathrm{capacities,} \mathrm{the} \mathrm{pareto} \mathrm{front} \mathrm{yields}$ 
panel sizes of 2.7-3 kW with the best trade-off observed at $3 \mathrm{~kW}$. Thus, it follows that roof-top PV installations in the $1-3 \mathrm{~kW}$ range offer a win-win situation only at the maximum panel size of $3 \mathrm{~kW}$ for FiT $>=2.2 \mathrm{Rs} / \mathrm{kWh}$.

TABLE. 3. SENSITIVITY OF PROSUMER SAVINGS AND UTILITY PROFIT TO PV SIZE (1-3 KW) AND FIT

\begin{tabular}{|c|c|c|c|c|c|c|c|c|c|c|}
\hline \multicolumn{11}{|c|}{ Prosumer Saving (\%) } \\
\hline \multicolumn{2}{|c|}{ FiT (Rs/kWh) } & 1 & 1.4 & 1.8 & 2.2 & 2.6 & 3 & 3.4 & 3.8 & 4.2 \\
\hline \multirow{4}{*}{$\begin{array}{c}\text { PV } \\
\text { size } \\
(\mathbf{k W})\end{array}$} & 2.7 & $49.4 \%$ & $54.4 \%$ & $59.5 \%$ & $64.5 \%$ & $69.6 \%$ & $74.7 \%$ & $79.7 \%$ & $84.8 \%$ & $89.8 \%$ \\
\hline & 2.8 & $48.3 \%$ & $53.7 \%$ & $59.1 \%$ & $64.5 \%$ & $70.0 \%$ & $75.4 \%$ & $80.8 \%$ & $86.3 \%$ & $91.7 \%$ \\
\hline & 2.9 & $47.1 \%$ & $52.9 \%$ & $58.7 \%$ & $64.5 \%$ & $70.3 \%$ & $76.2 \%$ & $82.0 \%$ & $87.8 \%$ & $93.6 \%$ \\
\hline & 3 & $46.0 \%$ & $52.2 \%$ & $58.4 \%$ & $64.5 \%$ & $70.7 \%$ & $76.9 \%$ & $83.1 \%$ & $89.3 \%$ & $95.4 \%$ \\
\hline \multicolumn{11}{|c|}{ Utility Profit (\%) } \\
\hline \multirow{4}{*}{$\begin{array}{c}\text { PV } \\
\text { size } \\
(\mathbf{k W})\end{array}$} & 2.7 & $35.4 \%$ & $33.5 \%$ & $31.6 \%$ & $29.6 \%$ & $27.7 \%$ & $25.8 \%$ & $23.8 \%$ & $21.9 \%$ & $20.0 \%$ \\
\hline & 2.8 & $37.8 \%$ & $35.7 \%$ & $33.7 \%$ & $31.6 \%$ & $29.5 \%$ & $27.4 \%$ & $25.3 \%$ & $23.3 \%$ & $21.2 \%$ \\
\hline & 2.9 & $40.2 \%$ & $38.0 \%$ & $35.7 \%$ & $33.5 \%$ & $31.3 \%$ & $29.1 \%$ & $26.9 \%$ & $24.6 \%$ & $22.4 \%$ \\
\hline & 3 & $42.5 \%$ & $40.2 \%$ & $37.8 \%$ & $35.4 \%$ & $33.1 \%$ & $30.7 \%$ & $28.4 \%$ & $26.0 \%$ & $23.6 \%$ \\
\hline
\end{tabular}

188

190

191

192

TABLE. 4. SENSITIVITY OF PROSUMER SAVINGS AND UTILITY PROFIT TO PV SIZE (3-5 KW) AND FIT

\begin{tabular}{|c|c|c|c|c|c|c|c|c|c|c|}
\hline \multicolumn{11}{|c|}{ Prosumer Saving (\%) } \\
\hline \multicolumn{2}{|c|}{ FiT (Rs/kWh) } & $\mathbf{1}$ & 1.4 & 1.8 & 2.2 & 2.6 & 3 & 3.4 & 3.8 & 4.2 \\
\hline \multirow{4}{*}{$\begin{array}{c}\text { PV } \\
\text { size } \\
(\mathbf{k W})\end{array}$} & 4.7 & $31.9 \%$ & $37.1 \%$ & $42.3 \%$ & $47.6 \%$ & $52.8 \%$ & $58.0 \%$ & $63.2 \%$ & $68.4 \%$ & $73.7 \%$ \\
\hline & 4.8 & $30.8 \%$ & $36.2 \%$ & $41.7 \%$ & $47.1 \%$ & $52.6 \%$ & $58.0 \%$ & $63.5 \%$ & $68.9 \%$ & $74.4 \%$ \\
\hline & 4.9 & $29.7 \%$ & $35.4 \%$ & $41.1 \%$ & $46.7 \%$ & $52.4 \%$ & $58.1 \%$ & $63.7 \%$ & $69.4 \%$ & $75.1 \%$ \\
\hline & 5 & $28.7 \%$ & $34.5 \%$ & $40.4 \%$ & $46.3 \%$ & $52.2 \%$ & $58.1 \%$ & $64.0 \%$ & $69.9 \%$ & $75.8 \%$ \\
\hline \multicolumn{11}{|c|}{ Utility Profit (\%) } \\
\hline \multirow{4}{*}{$\begin{array}{c}\text { PV } \\
\text { size } \\
(\mathbf{k W})\end{array}$} & 4.7 & $35.6 \%$ & $33.5 \%$ & $31.4 \%$ & $29.3 \%$ & $27.1 \%$ & $25.0 \%$ & $22.9 \%$ & $20.8 \%$ & $18.7 \%$ \\
\hline & 4.8 & $37.1 \%$ & $34.9 \%$ & $32.7 \%$ & $30.5 \%$ & $28.3 \%$ & $26.1 \%$ & $23.9 \%$ & $21.7 \%$ & $19.5 \%$ \\
\hline & 4.9 & $38.6 \%$ & $36.3 \%$ & $34.0 \%$ & $31.7 \%$ & $29.4 \%$ & $27.1 \%$ & $24.8 \%$ & $22.5 \%$ & $20.2 \%$ \\
\hline & 5 & $40.1 \%$ & $37.7 \%$ & $35.3 \%$ & $32.9 \%$ & $30.5 \%$ & $28.1 \%$ & $25.8 \%$ & $23.4 \%$ & $21.0 \%$ \\
\hline
\end{tabular}

TABLE. 5. SENSITIVITY OF PROSUMER SAVINGS AND UTILITY PROFIT TO PV SIZE (5-8 KW) AND FIT

\begin{tabular}{|c|c|c|c|c|c|c|c|c|c|c|}
\hline \multicolumn{11}{|c|}{ Prosumer Saving (\%) } \\
\hline \multicolumn{2}{|c|}{ FiT (Rs/kWh) } & 1 & 1.4 & 1.8 & 2.2 & 2.6 & 3 & 3.4 & 3.8 & 4.2 \\
\hline \multirow{4}{*}{$\begin{array}{c}\text { PV } \\
\text { size } \\
(\mathrm{kW})\end{array}$} & 7.7 & $32.5 \%$ & $37.8 \%$ & $43.1 \%$ & $48.4 \%$ & $53.7 \%$ & $59.0 \%$ & $64.4 \%$ & $69.7 \%$ & $75.0 \%$ \\
\hline & 7.8 & $31.8 \%$ & $37.2 \%$ & $42.7 \%$ & $48.2 \%$ & $53.6 \%$ & $59.1 \%$ & $64.5 \%$ & $70.0 \%$ & $75.4 \%$ \\
\hline & 7.9 & $31.1 \%$ & $36.7 \%$ & $42.3 \%$ & $47.9 \%$ & $53.5 \%$ & $59.1 \%$ & $64.7 \%$ & $70.3 \%$ & $75.9 \%$ \\
\hline & 8 & $30.4 \%$ & $36.2 \%$ & $41.9 \%$ & $47.6 \%$ & $53.4 \%$ & $59.1 \%$ & $64.8 \%$ & $70.6 \%$ & $76.3 \%$ \\
\hline \multicolumn{11}{|c|}{ Utility Profit (\%) } \\
\hline \multirow{4}{*}{$\begin{array}{c}\text { PV } \\
\text { size } \\
(\mathbf{k W})\end{array}$} & 7.7 & $39.4 \%$ & $37.0 \%$ & $34.6 \%$ & $32.2 \%$ & $29.7 \%$ & $27.3 \%$ & $24.9 \%$ & $22.4 \%$ & $20.0 \%$ \\
\hline & 7.8 & $40.5 \%$ & $38.0 \%$ & $35.5 \%$ & $33.0 \%$ & $30.5 \%$ & $28.0 \%$ & $25.5 \%$ & $23.0 \%$ & $20.5 \%$ \\
\hline & 7.9 & $41.5 \%$ & $39.0 \%$ & $36.4 \%$ & $33.9 \%$ & $31.3 \%$ & $28.7 \%$ & $26.2 \%$ & $23.6 \%$ & $21.1 \%$ \\
\hline & 8 & $42.6 \%$ & $40.0 \%$ & $37.3 \%$ & $34.7 \%$ & $32.1 \%$ & $29.5 \%$ & $26.8 \%$ & $24.2 \%$ & $21.6 \%$ \\
\hline
\end{tabular}


Higher the PV size, more will be the export so that the utility is able to procure energy at FiT. Since the FiT is lower than ACoS, this results in a reduction in cost of procurement. The energy procured from the prosumers is sold at ABR which is higher than the FiT, thereby yielding a better profit for the utility. For 1-3 kW PV capacities, the EMI outgo is compensated by the receipts from the sale of energy only at FiTs greater than or equal to $2.2 \mathrm{Rs} / \mathrm{kWh}$. This results in an increasing trend in utility profit with increasing PV sizes. For capacities in the ranges 3-5 kW and 5-8 kW, the EMI is compensated only at FiTs of $3 \mathrm{Rs} / \mathrm{kWh}$ and above because of the higher EMI in these ranges (see Tables 4 and 5). EMI variation is found to be non-linear and non-uniform for variations in PV capacities. At lower PV sizes (where $E_{d p}>=E_{g p}$ ), utility profit does not change with increasing FiT as there is no export. The profit is contributed only by the fixed charges plus the revenue from the consumers billed at ABR. In a low FiT regime, the prosumer savings peak at a PV capacity where the generation balances the demand. Therefore, it is recommended that a PV capacity that results in balancing demand and generation be chosen if the FiT's are low, to maximize prosumer savings.

Table 6 summarizes the optimal ranges of FiTs, $E_{d p}$, PV capacities and the corresponding prosumers savings and utility profits. It is found that for existing $\mathrm{ABR} \& \mathrm{ACoS}$ values, the $E_{d p}$ ranges from $50 \%$ to $90 \%$ of the local solar generation. The optimal FiT ranges should be from Rs 2.2 to 4.1 per $\mathrm{kWh}$ for lower PV range 1-3 kW and from Rs 3 to 4.1 per $\mathrm{kWh}$ for the higher PV range of 3-8 $\mathrm{kW}$. It is observed that a profit of at least $10 \%$ is earned by the utility only at maximum PV capacities of $3 \mathrm{~kW}, 5 \mathrm{~kW}$ and $8 \mathrm{~kW}$ respectively for the ranges under consideration. Compared to prosumer savings, utility profits are found to be relatively low in the range 10-28 \% across PV capacities because of the prevailing $\mathrm{ABR}$ being less than $\mathrm{ACoS}$ for MSEDCL.

TABLE. 6. ANALYSIS FOR DIFFERENT PV CAPACITY RANGES MSEDCL

\begin{tabular}{|l|l|l|l|l|l|}
\hline $\begin{array}{l}\text { PV panel size } \\
(\mathbf{k W})\end{array}$ & $\begin{array}{l}\text { FiT range } \\
(\mathbf{R s} / \mathbf{k W h})\end{array}$ & $\begin{array}{l}\boldsymbol{E}_{\boldsymbol{d} \boldsymbol{p}} \text { range } \\
(\boldsymbol{\%})\end{array}$ & $\begin{array}{l}\text { Optimum PV } \\
\text { Capacity }(\mathbf{k W})\end{array}$ & $\begin{array}{l}\text { Prosumer Saving } \\
(\boldsymbol{\%})\end{array}$ & $\begin{array}{l}\text { Utility Profit } \\
(\boldsymbol{\%})\end{array}$ \\
\hline $\mathbf{1 - 3}$ & $2.2-4.1$ & $55-95$ & 3 & $51-66$ & $11-28$ \\
\hline $\mathbf{3 - 5}$ & $3-4.1$ & $60-90$ & 5 & $58-66$ & $10-24$ \\
\hline $\mathbf{5 - 8}$ & $3-4.1$ & $60-90$ & 8 & $59-68$ & $10-24$ \\
\hline
\end{tabular}
considered for the study. 


\begin{tabular}{|l|l|l|l|l|l|}
\hline $\begin{array}{l}\text { PV panel size } \\
(\mathbf{k W})\end{array}$ & $\begin{array}{l}\text { FiT range } \\
(\mathbf{R s} / \mathbf{k W h})\end{array}$ & $\begin{array}{l}\boldsymbol{E}_{\boldsymbol{d} p} \text { range } \\
(\boldsymbol{\%})\end{array}$ & $\begin{array}{l}\text { Optimum PV } \\
\text { Capacity }(\mathbf{k W})\end{array}$ & $\begin{array}{l}\text { Prosumer Saving } \\
(\mathbf{\%})\end{array}$ & $\begin{array}{l}\text { Utility Profit } \\
(\mathbf{\%})\end{array}$ \\
\hline $\mathbf{1 - 3}$ & $1-4.2$ & $60-130$ & 3 & $51-70$ & $25-40$ \\
\hline $\mathbf{3 - 5}$ & $1-4.2$ & $60-150$ & 5 & $44-70$ & $21-45$ \\
\hline $\mathbf{5 - 8}$ & $1-4.2$ & $55-135$ & 8 & $50-75$ & $20-48$ \\
\hline
\end{tabular}

218

\section{Case 2: TATA Power (Delhi)}

The pareto-fronts for different PV capacities are shown in Fig.5. A trend similar to that in Case 1 is seen

222 where the best trade-offs in terms of percentages are observed for PV capacities in the range 1-3 kW. On the other

223 hand, in absolute terms, a win-win situation occurs at PV capacities in the range 5-8 kW. From Table 8, it is found that

224 for the prevailing ABR \& ACoS values, the optimal $E_{d p}$ ranges from $50 \%$ to $60 \%$ of $E_{g p}$. Further, the optimal FiT

225 ranges from Rs 1 to 1.3 per $\mathrm{kWh}$ for lowest PV capacities 1-3 kW and from Rs 1 to 1.5 per $\mathrm{kWh}$ for higher PV capacities

226 of 3-8 kW. From Table 9, it is found that if the value of ABR is set to $120 \%$ of ACoS, then the profit is significantly

227 improved from 8-13\% to 20-48 \% across PV capacities. The rise in profits is due to the higher revenue for the utility

228 on account of the increase in ABR. The prevailing ABR is $4.96 \mathrm{Rs} / \mathrm{kWh}$ and ACoS is $7.31 \mathrm{Rs} / \mathrm{kWh}$ for TATA power.

229 In this case, the utility profits and prosumer savings are less compared to MSEDCL, as the prevailing ABR is much

230 less than ACoS for TATA Power.

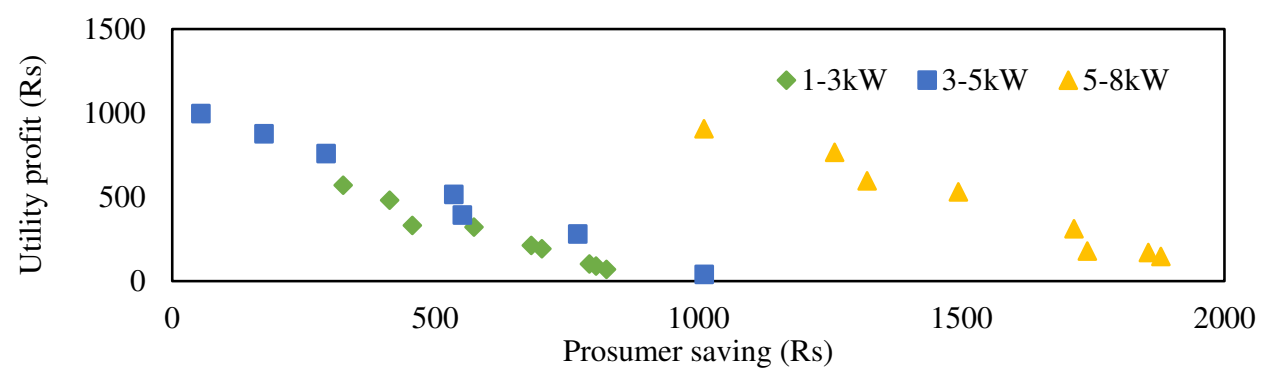

Fig. 5. Pareto optimal points for different PV ranges

TABLE. 8. ANALYSIS FOR DIFFERENT PV CAPACITY RANGES TATA POWER

\begin{tabular}{|l|l|l|l|l|l|}
\hline $\begin{array}{l}\text { PV panel size } \\
(\mathbf{k W})\end{array}$ & $\begin{array}{l}\text { FiT range } \\
(\mathbf{R s} / \mathbf{k W h})\end{array}$ & $\begin{array}{l}\boldsymbol{E}_{\boldsymbol{d} \boldsymbol{p}} \text { range } \\
(\boldsymbol{\%})\end{array}$ & $\begin{array}{l}\text { Optimum PV } \\
\text { Capacity }(\mathbf{k W})\end{array}$ & $\begin{array}{l}\text { Prosumer Saving } \\
(\boldsymbol{\%})\end{array}$ & $\begin{array}{l}\text { Utility Profit } \\
(\boldsymbol{\%})\end{array}$ \\
\hline $\mathbf{1 - 3}$ & $1-1.3$ & 60 & 3 & $13-17$ & $11-13$ \\
\hline
\end{tabular}




\begin{tabular}{|l|l|l|l|l|l|}
$\mathbf{3 - 5}$ & $1-1.2$ & 50 & 5 & $2-6$ & $11-13$ \\
\hline $\mathbf{5 - 8}$ & $1.2-1.5$ & 60 & 8 & $16-20$ & $8-9$ \\
\hline
\end{tabular}

TABLE. 9. ANALYSIS FOR DIFFERENT PV CAPACITY RANGES WITH PROPOSED ABR

\begin{tabular}{|l|l|l|l|l|l|}
\hline $\begin{array}{l}\text { PV panel size } \\
(\mathbf{k W})\end{array}$ & $\begin{array}{l}\text { FiT range } \\
(\mathbf{R s} / \mathbf{k W h})\end{array}$ & $\begin{array}{l}\boldsymbol{E}_{\boldsymbol{d} \boldsymbol{p}} \text { range } \\
(\boldsymbol{\%})\end{array}$ & $\begin{array}{l}\text { Optimum PV } \\
\text { Capacity }(\mathbf{k W})\end{array}$ & $\begin{array}{l}\text { Prosumer Saving } \\
(\boldsymbol{\%})\end{array}$ & $\begin{array}{l}\text { Utility Profit } \\
(\boldsymbol{\%})\end{array}$ \\
\hline $\mathbf{1 - 3}$ & $1.1-4$ & $55-130$ & 3 & $48-69$ & $25-48$ \\
\hline $\mathbf{3 - 5}$ & $1.3-4.1$ & $50-145$ & 5 & $45-72$ & $22-43$ \\
\hline $\mathbf{5 - 8}$ & $1-4.2$ & $55-135$ & 8 & $48-68$ & $20-48$ \\
\hline
\end{tabular}

235

236 Case 3: TANGEDCO (Tamil Nadu)

237 The pareto optimal points for different PV ranges are shown in Fig.6. From Table 10, it is found that for 238 prevailing $\mathrm{ABR} \& \mathrm{ACoS}$ values, the optimal $E_{d p}$ ranges from 50-60\% of $E_{g p} \&$ optimal FiT ranges from Rs 1-1.3 per $239 \mathrm{kWh}$ respectively for lower PV range $1-3 \mathrm{~kW}$ and above $1.8 \mathrm{Rs} / \mathrm{kWh}$ for higher PV range from 3 to $8 \mathrm{~kW}$. From Table 24011 , it is observed that if the value of ABR is set to $120 \%$ of $\mathrm{ACoS}$, then the profit gets significantly increased to 19$24146 \%$ from 8-15 \% across PV capacities. This can be attributed to the low prevailing ABR values as is the case with 242 TATA power (refer Case 2).

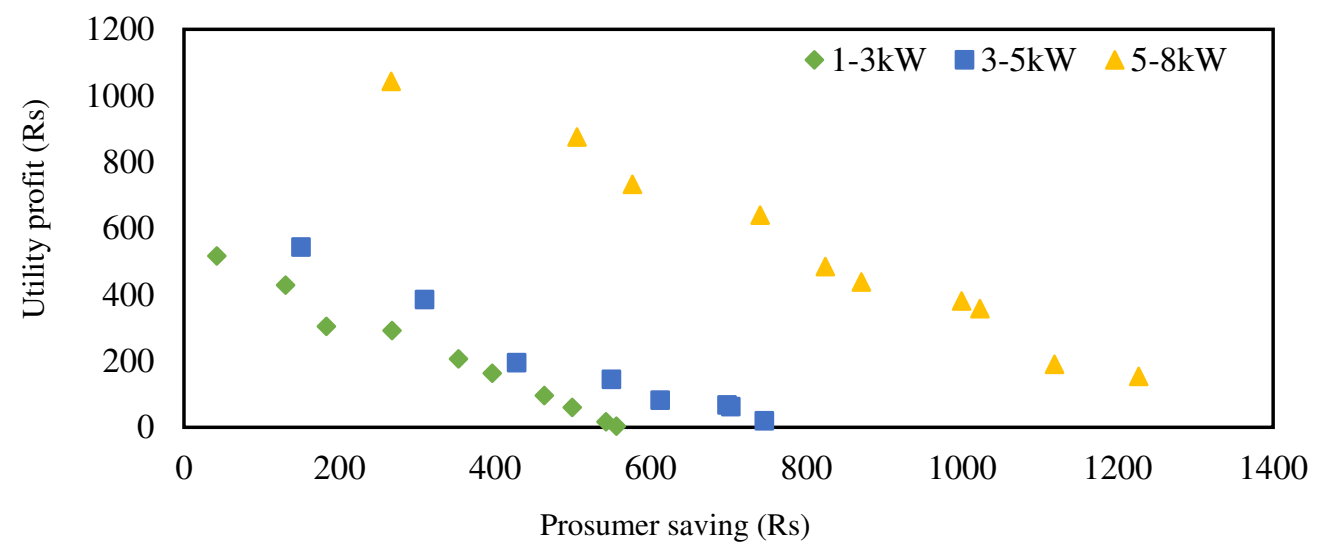

Fig. 6. Pareto optimal points for different PV ranges

TABLE. 10. ANALYSIS FOR DIFFERENT PV CAPACITY RANGES TANGEDCO

\begin{tabular}{|l|l|l|l|l|l|}
\hline $\begin{array}{l}\text { PV panel size } \\
(\mathbf{k W})\end{array}$ & $\begin{array}{l}\text { FiT range } \\
(\mathbf{R s} / \mathbf{k W h})\end{array}$ & $\begin{array}{l}\boldsymbol{E}_{\boldsymbol{d} \boldsymbol{p}} \text { range } \\
(\boldsymbol{\%})\end{array}$ & $\begin{array}{l}\text { Optimum PV } \\
\text { Capacity }(\mathbf{k W})\end{array}$ & $\begin{array}{l}\text { Prosumer Saving } \\
(\boldsymbol{\%})\end{array}$ & $\begin{array}{l}\text { Utility Profit } \\
(\boldsymbol{\%})\end{array}$ \\
\hline $\mathbf{1 - 3}$ & $1-1.3$ & 60 & 3 & $2-6$ & $12-15$ \\
\hline $\mathbf{3 - 5}$ & 1.8 & 50 & 5 & 5 & 8 \\
\hline
\end{tabular}




\begin{tabular}{|l|l|l|l|l|l|}
\hline $\mathbf{5 - 8}$ & $1.2-1.5$ & 60 & 8 & $5-10$ & $10-12$ \\
\hline
\end{tabular}

TABLE. 11. ANALYSIS FOR DIFFERENT PV CAPACITY RANGES WITH PROPOSED ABR

\begin{tabular}{|l|l|l|l|l|l|}
\hline $\begin{array}{l}\text { PV panel size } \\
(\mathbf{k W})\end{array}$ & $\begin{array}{l}\text { FiT range } \\
(\mathbf{R s} / \mathbf{k W h})\end{array}$ & $\begin{array}{l}\boldsymbol{E}_{\boldsymbol{d} \boldsymbol{p}} \text { range } \\
(\boldsymbol{\%})\end{array}$ & $\begin{array}{l}\text { Optimum PV } \\
\text { Capacity }(\mathbf{k W})\end{array}$ & $\begin{array}{l}\text { Prosumer Saving } \\
(\boldsymbol{\%})\end{array}$ & $\begin{array}{l}\text { Utility Profit } \\
(\boldsymbol{\%})\end{array}$ \\
\hline $\mathbf{1 - 3}$ & $1.6-4.2$ & $50-130$ & 3 & $44-62$ & $22-38$ \\
\hline $\mathbf{3 - 5}$ & $1-4.1$ & $55-145$ & 5 & $39-64$ & $20-44$ \\
\hline $\mathbf{5 - 8}$ & $1-4.1$ & $50-140$ & 8 & $38-63$ & $19-46$ \\
\hline
\end{tabular}

\section{Conclusion and Policy Implications}

- A cost-benefit analysis of the consumer-centric business model for domestic rooftop solar PV installations in India is carried out to identify optimal policy parameters yielding reasonable trade-offs in stakeholder benefits. To this end, a multi-objective optimization problem is formulated, with utility profit and prosumer savings as objectives.

- The results indicate that for prevailing ABR and ACoS values, the local rooftop PV capacity should be chosen such that there is net export of power by the prosumer. This is due to lower prevailing ABR compared to ACoS. On the other hand, when prosumer demand exceeds generation, the utility incurs losses due to lower ABR.

- It is observed that the maximum PV panel capacity yields better trade-offs for all the three ranges considered. For lower capacity installations, both prosumer savings and utility profits are affected with the prevailing values of FiT and ACoS.

- When ABR is set to $120 \%$ of $\mathrm{ACoS}$, the pareto front yields a wider range of FiT and $E_{d p}$ with reasonable tradeoffs. This is because the major share in prosumer savings is from solar energy self-consumption. At the same time, the low FiT values yield better utility profits because of higher ABR. Even PV installations of smaller capacities turn out to be profitable to the utility and beneficial to the prosumer at higher ABR values. Hence, tariff rationalization is recommended to make large-scale adoption of rooftop PV by domestic consumers a winwin proposition. However, drastic changes in residential tariff would face socio-political challenges

- In case of MSEDCL, for a guaranteed minimum utility profit of $10 \%$, the average energy demand of prosumer should be around $70 \%$ of $E_{g p}$. For TATA power, for the same targeted minimum utility profit of $10 \%$, the 
average energy demand of prosumer turns out to be around $56 \%$ of $E_{g p}$. In case of TANGEDCO, the minimum profit is guaranteed at an average prosumer demand of $56 \%$ of $E_{g p}$.

- Across the utilities, it is seen that with the prevailing ABR and ACoS values, if the prosumers consume 50 to $60 \%$ of local solar PV generation, both the utility and prosumer are benefited.

\section{Acronyms}

\begin{tabular}{|l|l|}
\hline ABR & Average Billing Rate \\
\hline ACoS & Average Cost of Supply \\
\hline EB & Electricity Board \\
\hline EPC & Engineering, Procurement and Construction \\
\hline FiT & Feed-in-Tariff \\
\hline MSEDCL & Maharashtra State Electricity Distribution Corporation Limited \\
\hline PPA & Power Purchase Agreement \\
\hline TANGEDCO & Tamilnadu Generation and Distribution Corporation Limited \\
\hline
\end{tabular}

Nomenclature

\begin{tabular}{|l|l}
\hline$a b r$ & Average billing rate $(\mathrm{Rs} / \mathrm{kWh})$ \\
\hline$a c o s$ & Average cost of supply $(\mathrm{Rs} / \mathrm{kWh})$
\end{tabular}




\begin{tabular}{|c|c|}
\hline Bill $_{\text {with solar }}$ & Monthly bill paid by prosumer to utility with solar (Rs) \\
\hline Bill $_{\text {without solar }}$ & Monthly bill paid by prosumer to utility without solar (Rs) \\
\hline$E_{D}$ & Total energy demand (kWh) \\
\hline$E_{g p}$ & Total energy generation by prosumer $(\mathrm{kWh})$ \\
\hline$E_{d p}$ & Energy demand of prosumer (kWh) \\
\hline$E_{d c}$ & Energy demand of consumer $(\mathrm{kWh})$ \\
\hline $\operatorname{Exp}_{u t i}$ & Expense of utility (Rs) \\
\hline$F C$ & Fixed charge (Rs) \\
\hline $\mathrm{k}$ & Binary constant taking value of 1 or 0 \\
\hline$n_{c}$ & Number of consumers \\
\hline$n_{p}$ & Number of prosumers \\
\hline $\mathrm{n}$ & Payback period (months) \\
\hline $\mathrm{p}$ & Total installation cost of PV panel (Rs) \\
\hline $\mathrm{r}$ & Monthly rate of interest (\%) \\
\hline$R e v_{u t i}$ & Revenue of utility (Rs) \\
\hline Saving $_{\text {pro }}$ & Saving of prosumer (Rs) \\
\hline
\end{tabular}

Declarations

287 Ethics approval and consent to participate

288 Not Applicable

289 Consent for publication

290 Not Applicable

291 Availability of data and materials

292 All data generated or analysed during this study are included in this published article.

293 Competing interests

294 The authors declare that they have no competing interests 


\section{Funding}

296 The financial support is provided by SPARC, Ministry of Human Resources and Development, Government of India 297 under the research Grant No. SPARC/2018-2019/P921/SL dated 15-03-2019.

\section{Authors' contributions}

299 VM: Conceptualization, Methodology, Writing - original draft, Writing - review \& editing, Supervision, Project 300 administration, Funding acquisition. HRDS: Conceptualization, Methodology, Writing - original draft, Writing 301 review \& editing, Supervision, Project administration. GP: Data curation, Software, Writing - original draft, Formal 302 analysis. JM: Data curation, Software, Writing - original draft, Formal analysis. RCU: Supervision, Investigation, 303 Project administration, NK: Conceptualization, Methodology, Supervision. KT: Supervision, Project administration 304 Funding acquisition. SB: Supervision, Project administration Funding acquisition. All authors read and approved the 305 final manuscript.

\section{Acknowledgements}

307 Not Applicable

308 Authors' information (optional)

$309{ }^{1}$ Department of Electrical and Electronics Engineering, National Institute of Technology Tiruchirappalli, TN, India

$310 \quad{ }^{2}$ SIERS Research Laboratory, Department of Electronics and Communication Engineering, Amrita School of

311 Engineering, Coimbatore, Amrita Vishwa Vidyapeetham, India

$312{ }^{3}$ Auroville Consulting, Kalpana Community, Auroville, TN, India

$313{ }^{4}$ Transgrid Construction Subdivision, Kerala State Electricity Board Limited, Kerala, India

$314{ }^{5}$ Department of Electrical Engineering, The Hong Kong Polytechnic University, Hong Kong

\section{REFERENCES}

1. Malti Goel (2016), Solar rooftop in India: Policies, challenges and outlook, Green Energy \& Environment, Volume 1, Issue 2, Pages 129-137,

317 ISSN 2468-0257, https://doi.org/10.1016/j.gee.2016.08.003

318 2. Ministry of New and Renewable Energy (MNRE) (2021), https://www.mnre.gov.in/

319 3. TEDA. (2019) Tamil Nadu Solar Energy Policy 2019. Available at: http://teda.in/wp-content/ uploads/2019/02/SOLARPOLICY2019.pdf 320 (accessed on 10th April 2020).

321 4. Srikanth, R., (2018). India's sustainable development goals-Glide path for India's power sector. Energy policy, 123, pp.325-336. 
5. Rahul Verma, Drake D. Hernandez, Varun Sivaram, Varun Rai, (2016) A national certification scheme to enhance trust and quality in the Indian residential solar PV market, The Electricity Journal, Volume 29, Issue 6, Pages 11-14, ISSN 10406190, https://doi.org/10.1016/j.tej.2016.07.005

6. Neeraj Kuldeep, Selna Saji, and Kanika Chawla (2018) 'Scaling Rooftop Solar: Powering India's Renewable Energy Transition with Households and DISCOMs, Council on Energy, Environment and Water (CEEW), June 2018

7. Tongsopit, S., Moungchareon, S., Aksornkij, A. and Potisat, T., (2016). Business models and financing options for a rapid scale-up of rooftop solar power systems in Thailand. Energy Policy, 95, pp.447-457

8. Cliff Rochlin,(2021) A case study: California utilities and the progressive business model, The Electricity Journal, Volume 34, Issue 5, 106959, ISSN 1040-6190, https://doi.org/10.1016/j.tej.2021.106959.Rashi Singh, Rishabh Sethi, Robin Mazumdar, Solar Rooftop: Perspective of Discoms, TERI Press, The Energy and Resources Institute, 2019

9. La Monaca, S., \& Ryan, L. (2017). Solar PV where the sun doesn’t shine: Estimating the economic impacts of support schemes for residential PV with detailed net demand profiling. Energy Policy, 108, 731-741.

10. Best, R. and Trück, S., (2020). Capital and policy impacts on Australian small-scale solar installations. Energy Policy, 136, p.111082

11. Alqahtani, B.J. and Patiño-Echeverri, D., (2019). Combined effects of policies to increase energy efficiency and distributed solar generation: A case study of the Carolinas. Energy Policy, 134, p.110936.

12. Madathil, D., Pandi, V.R., Nair, M.G. et al. (2021) Net Zero Energy in a Residential Building Using Heuristic Optimization Solution. J Control Autom Electr Syst 32, 458-471. https://doi.org/10.1007/s40313-020-00685-7

13. Li, C. and Shen, B., (2019). Accelerating renewable energy electrification and rural economic development with an innovative business model: A case study in China. Energy Policy, 127, pp.280-286.

14. Lukanov, B.R. and Krieger, E.M., (2019). Distributed solar and environmental justice: Exploring the demographic and socio-economic trends of residential PV adoption in California. Energy Policy, 134, p.110935

15. Palm, A. and Lantz, B., (2020). Information dissemination and residential solar PV adoption rates: The effect of an information campaign in Sweden. Energy Policy, 142, p.111540.

16. Pearce, P. and Slade, R., (2018). Feed-in tariffs for solar microgeneration: Policy evaluation and capacity projections using a realistic agentbased model. Energy Policy, 116, pp.95-111.

17. Dutta, A. and Das, S., (2020). Adoption of grid-connected solar rooftop systems in the state of Jammu and Kashmir: A stakeholder analysis. Energy Policy, 140, p.111382.

18. M. Frey et al., (2017) "Elevating education of India's rural village girls through distance learning technology supported by sustainable electricity," 2017 IEEE Global Humanitarian Technology Conference (GHTC), 2017, pp. 1-8, doi: 10.1109/GHTC.2017.8239300.

19. Naïm R. Darghouth, Galen Barbose, Ryan Wiser, (2011) The impact of rate design and net metering on the bill savings from distributed PV for residential customers in California,Energy Policy,Volume 39, Issue 9, Pages 5243-5253, ISSN 0301-4215, https://doi.org/10.1016/j.enpol.2011.05.040.

20. Kottayil, S.K. (Ed.). (2020). Smart Microgrids (1st ed.). CRC Press. https://doi.org/10.1201/9780429325274

21. Gambhir Ashwin, Shantanu Dixit, Vishal Toro, Vijaypal Singh, (2012) Solar Rooftop PV in India: Need to Prioritize In-situ Generation for Self-consumption with Net-metering Approach, Policy Discussion Paper, Prayas Energy Group 

a discrete choice experiment. Energ Sustain Soc 11, 15. https://doi.org/10.1186/s13705-021-00291-8

23. Toby Couture, Yves Gagnon, (2010) An analysis of feed-in tariff remuneration models: Implications for renewable energy investment, Energy Policy, Volume 38, Issue 2, Pages 955-965, ISSN 0301-4215, https://doi.org/10.1016/j.enpol.2009.10.047.

24. V. Mohan, R. Suresh, J. G. Singh, W. Ongsakul and N. Madhu, (2017) "Microgrid Energy Management Combining Sensitivities, Interval and Probabilistic Uncertainties of Renewable Generation and Loads," in IEEE Journal on Emerging and Selected Topics in Circuits and Systems, vol. 7, no. 2, pp. 262-270, doi: 10.1109/JETCAS.2017.2679030

25. Zhe Li, Fergal Boyle, Anthony Reynolds, (2011) Domestic application of solar PV systems in Ireland: The reality of their economic viability, Energy, Volume 36, Issue 10, Pages 5865-5876, ISSN 0360-5442, https://doi.org/10.1016/j.energy.2011.08.036.

26. A. Campoccia, L. Dusonchet, E. Telaretti, G. Zizzo, (2014) An analysis of feed in tariffs for solar PV in six representative countries of the European Union, Solar Energy, Volume 107, Pages 530-542, ISSN 0038-092X, https://doi.org/10.1016/j.solener.2014.05.047.

27. Sopitsuda Tongsopit, (2015) Thailand's feed-in tariff for residential rooftop solar PV systems: Progress so far, Energy for Sustainable Development, Volume 29, Pages 127-134, ISSN 0973-0826, https://doi.org/10.1016/j.esd.2015.10.012.

28. Pushpendra Kumar Singh Rathore, Durg Singh Chauhan, Rudra Pratap Singh, (2019) Decentralized solar rooftop photovoltaic in India: On the path of sustainable energy security, Renewable Energy, Volume 131, Pages 297-307, ISSN 0960-1481, https://doi.org/10.1016/j.renene.2018.07.049.

29. Sapan Thapar, Seema Sharma, Ashu Verma, (2018) Analyzing solar auctions in India: Identifying key determinants, Energy for Sustainable Development, Volume 45, Pages 66-78, ISSN 0973-0826, https://doi.org/10.1016/j.esd.2018.05.003.

30. Eric O'Shaughnessy, Kristen Ardani, (2020) Distributed rate design: A review of early approaches and practical considerations for value of solar tariffs, The Electricity Journal, Volume 33, Issue 3, 106713, ISSN 1040-6190, https://doi.org/10.1016/j.tej.2020.106713.

31. Auroville Consulting (2020), Implementation Models for Distributed Solar Energy in Tamilnadu, Making solar a winning proposition for all stakeholders, Sustainable Energy Transformation Series. Available at: www.aurovilleconsulting.com/wp-admin/post.php? post $=3053$ \&action=edit

32. Kapardhi Bharadwaj, Karthik Ganesan, And Neeraj Kuldeep, (2018). CEEW Report Retail Tariffs for Electricity Consumers in Maharashtra https://www.ceew.in/sites/default/files/CEEW-Retail-Tariffs-for-Electricty-Consumers-in-Mumbai-10Jun18.pdf

33. Raghav Pachouri, Balaji Raparthi, Ashish Sharma, (2020). Cost of Supply of Electricity A Systemic Review and Way Forward for Indian DISCOMs Prepared for Distribution Utilities Forum (teriin.org/sites/default/files/2020-09/cost-supply-electricity.pdf)

384 34. MERC, (2020). Case of Maharashtra State Electricity Distribution Company Limited for Truing-up of Aggregate Revenue Requirement (ARR) of FY 2017-18 and FY 2018-19, Provisional Truing-up of ARR of FY 2019-20 and Projections of ARR and determination, FY 2020-21 to 2024-25. Available at: https://www.mahadiscom.in/consumer/wp-content/uploads/2020/03/Order-322-of-2019.pdf

35. TANGEDCO, (2017). One-page statement on tariff rates as in the TNERC order No:T.P.No.1 of 2017 DT:11.08.2017. Available at: https://www.tangedco.gov.in/linkpdf/ONE_PAGE_STATEMENT. Pdf

36. TATA Power Delhi distribution limited, (2020. Amended supplementary petition seeking revised (i) ARR for FY 2020-21, the first year of 4th MYT control period 2021 to 2023, in terms of the Delhi electricity regulatory commission 